\title{
Frameworks for analyzing the economic effects of climate change on outdoor recreation
}

\author{
W. Douglass Shaw ${ }^{1, *}$, John B. Loomis ${ }^{2}$ \\ ${ }^{1}$ Departments of Agricultural Economics and Recreation, Parks, and Tourism Sciences, Texas A\&M University, \\ College Station, Texas 77843-2124, USA \\ ${ }^{2}$ Department of Agricultural and Resource Economics, Colorado State University, Fort Collins, Colorado 80523-1172, USA
}

\begin{abstract}
Climate change is increasingly recognized as a major factor that may influence the recreational use of outdoor environments. Despite awareness of the pervasive effects of climate change, its effects on outdoor recreation have only recently been studied in detail. In this study we consider an economic framework that allows the modeling of the direct and indirect effects of climate change on users of recreation resources, via the impacts on natural resources upon which outdoor recreation depends. We also present a brief summary of selected empirical results bearing on climate-sensitive recreational activities. With the relatively small increases in temperature that are likely from near-term climate change, the number of people partaking in certain outdoor recreational activities - such as boating, golfing and beach recreation - is expected to increase by 14 to $36 \%$. Numbers partaking in other activities - most notably snow sports like skiing - will likely fall. We discuss critical areas of future research that are needed to provide more detailed estimates of changes in recreation activities (along with associated economic effects) that are likely to arise from climate change in the future.
\end{abstract}

KEY WORDS: Recreation · Tourism · Economics · Climate change

\section{INTRODUCTION}

In this study we provide the non-economist with some possible frameworks that could shed light on the important economic impacts of climate change on recreation and tourism. Climate change can affect the individual who is partaking in these activities, making her better, or worse, off. Recreation demands of impacted individuals can be summed to examine aggregate regional changes in demand. Such changes in demand eventually lead to changes in the supply of recreation and tourist-based activities, and to changes in resulting prices of activities, related outdoor recreation equipment, and related services. Finally, changes in tourist/recreation-based goods and service prices and quantities may ultimately influence other prices and quantities of goods and services in a 'general economic equilibrium' context. In adapting to or mitigating against adverse or beneficial climate change impacts, it is advantageous to quantify each of these com- ponents. In this study we discuss how several of these components can be analyzed within economic frameworks, with particular emphasis on the impacts on individuals who engage in outdoor recreation.

There is a well-established tradition in economics of linking environmental amenities (e.g. type of forest cover, fishing quality, or water quality or quantity) to individual or aggregate demand for outdoor recreation. Such environmental amenities can be affected by climate change, which, in turn, can affect recreational use, although these effects are difficult to predict because of the complexity of the systems involved (i.e. climate and the different environmental amenities). While impacts on outdoor recreation may seem minor in comparison to impacts on other economic sectors such as agriculture, outdoor recreation is a major element of the tourism industry, and tourism is one of the principal economic activities for some countries; it also represents $10 \%$ of the world's gross domestic product (e.g. see Berritella et al. 2006). 
Despite the importance of tourism, many recreation researchers have expressed concern that our understanding of climate change impacts on recreation is still in its infancy. As noted by Wall (1998, p 386): 'There is a dearth of rigorous studies of the possible implications of climate change for tourism and recreation...'. Several years later Hamilton \& Tol (2006) felt this situation had improved only slightly, as they indicated that mainstream tourism literature paid little attention to climate change. Readers interested in the evolution of recreation research on climate change should see Scott et al. (2006) and WTO (2003).

We will assume throughout this paper that climate change includes warming of regions of the planet, and thus, to probable changes in precipitation and a rise in the sea level; therefore, it has indirect impacts on many different ecosystems and habitats, many of which are sites that offer outdoor leisure and recreation activities. We do not want to get bogged down in debates over causes of climate change, nor do we want to spend time and space here discussing the science, so we refer the reader to the recently released report of the International Panel on Climate Change (IPCC), which provides an update on current thinking on the topics (see IPCC 2007).

Most ideas on the economics of climate change focus on the cost of greenhouse gas emissions (GHGs) and whether society can reduce GHGs via various economic incentives, such as carbon taxes. Some analyses have suggested that climate change might actually benefit some sectors of the economy, such as the Ricardian study by Mendelsohn et al. (1994) of agricultural impacts. This was one of the first empirical studies using cross-sectional analysis of climate change impacts on farmland values, and 2 of that study's authors later re-analyzed the data with different assumptions (adding irrigation to the model) (Mendelsohn \& Nordhaus 1999).

Much of the existing economic literature related to climate change neglects to mention the losses or gains in benefits from non-market goods such as recreation outings. Economists deem goods to be 'non-market' goods when there is no existing market that allows recovery of observable quantities and prices. The value for a non-market good is typically expressed as the individual's maximum willingness to pay (WTP) for the good, in keeping with the fact that the demand curve for an individual for a market good shows us her WTP for each quantity she demands. The problem with finding the WTP for a non-market good can be seen with this example. If a person takes a trip to hike on public land where there is no entry fee paid, do we even know about this trip? The answer is, probably not, unless a special survey has been implemented to collect this data. So, the hiking activity is not as easily quantified or valued as an individual's trip to play a round on a private golf course. Thus, while both the hiker and the golfer have an implicit WTP for their activity, it is much easier to observe the WTP for the golfer, presuming it has a relationship to the market price paid for the golf outing. We stress that the hiking trip has value too, and economists need to incorporate such activities into climate change impacts.

In the remainder of this study we consider such nonmarket impacts. We first briefly review some of what has been done to examine the relationship between climate change and leisure or recreation thus far, and then lay out 2 formal economic models that focus on the connections between climate and recreation. Connections between prices paid for recreational activities, equipment, and related services and the individual's WTP are considered in relation to this. We conclude by discussing the research gaps that exist today, which more or less provide a menu for future research in this area.

\section{CLIMATE CHANGE AND RECREATION: LITERATURE REVIEW}

Economic considerations relating climate change to recreation can likely best be split into 2 broad categories: (1) microeconomic decision making (What do one or more individuals do in response to climate change, and why?) and (2) general equilibrium (How do such decisions affect the whole economy, with all of the possible feedback effects considered?).

As an example, under Category 1, we consider individual recreational activities, such as whether a person takes a trip to go salmon fishing, where she goes, and how long she stays. Typically, of course, the data collection process involves obtaining as many respondents in the sample as possible to investigate such behavior. In Category 2, we should consider the ramifications of the salmon trips as they relate to other decisions each individual makes (How much money do they then spend on other types of leisure?) and to the responses of suppliers across the spectrum of impacted markets (for example, how much income do salmon fishing guides in the host region take in, and on what do they spend this income?). Simple economic analysis suggests that, as demands and supplies change, market equilibrium prices (those market prices that generally appear to hold with some stability unless there are significant market shocks or changes) might also change. These prices can include the observable market prices of tourist and recreation activities (where fees are charged), but also prices of related equipment, lodging, and labor (wages in the tourism industry). 
Literature relating climate change to leisure, recreation, and tourism is now rapidly increasing each year, but there is also an ongoing debate regarding the robustness and validity of many key results (see Bigano et al. 2006, Gössling \& Hall 2006). For convenience here, we will split the recreation-related literature into 'individual/microeconomic demand' studies and 'expenditure/impact' studies; we note that some existing single studies examine both types of impacts. What most laypersons interested in the economic impacts of climate change on tourism would probably like to know falls into the second class. These studies include assessments of whether climate change will reduce total or aggregate recreation or diminish the tourism sector (as well as the accompanying expenditures that such users make) and, if so, by how much. A reduction in total visitation to a host community and reduced expenditures are easily understood by many to be potentially damaging economic impacts. However, at the heart of these studies is an underlying premise that an individual can, and will, reduce her recreation visits when a factor changes that is negatively related to individual visitation.

\subsection{Total/aggregate visitation studies}

To provide background information, we consider some estimates of the percentage changes in recreational visitation (some of these data are presented in Table 1). There, the Mendelsohn \& Markowski (1999) estimates are gleaned from an analysis of impacts for each state in the conterminous United States. Changes in visitation are likely to vary across regions of the United States and throughout the world; however, Mendelsohn \& Markowski (1999) cite a Canadian study of skiing impacts that shows a loss of ski days ranging from 40 to $70 \%$, a range that encompasses the 2 estimates in Table 1. Another study examines the impacts on tourism, including adaptation, in the European Alps (Agrawala 2007). This OECD report suggests that the number of snow-reliable ski areas in Austria, France, Germany, Italy, and Switzerland, will fall from 609 to slightly over 200 areas, with a $4^{\circ} \mathrm{C}$ warming of the climate. Similarly, Bürki et al. (2003) examine the consequences of warming on Swiss ski areas, with similar estimates of a drop in availability. Based on a survey of skier preference, $49 \%$ of skiers would choose another ski resort when snow conditions are poor at one area, and $32 \%$ of skiers would ski less often. The basic point is that there is evidence that visitation will be influenced by climate change, and, for some activities, the effect will be substantial.

Naturally, such overall total reductions in skiing and other kinds of activities can reduce the accompanying
Table 1. Examples of changes in visitor days with climate change impacts $\left(2.5^{\circ} \mathrm{C}\right.$ increase by 2050). L\&C: Loomis \& Crespi (1999); M\&M: Mendelsohn \& Markowski (1999). Note: M\&M estimates are averaged over states analyzed across the USA

\begin{tabular}{|lcc|}
\hline Activity & L\&C (\%) & M\&M (\%) \\
\hline Boating & 9.2 & 36.1 \\
Camping & -2.0 & -12.7 \\
Fishing & 3.5 & 39.0 \\
Golf & 13.6 & 4.0 \\
Hunting & -1.2 & No change \\
Snow skiing & -52.0 & -39.0 \\
Wildlife viewing & -0.1 & -38.4 \\
Beach recreation & 14.1 & Not estimated \\
Watercourse recreation & 3.4 & Included in boating \\
Gain in visitor benefits & 2.74 & 2.80 \\
(in billion \$US) & & \\
\hline
\end{tabular}

total expenditures that would have been made in specific host communities were it not for the adverse effects of climate change. For example, Mendelsohn \& Markowski (1999) state that, if skiing in the United States were reduced by 40 to $70 \%$, it would result in a total loss of \$US 1.7 billion annually. This should be viewed carefully because a loss in the United States may be a gain to another country with sufficient skiing opportunities. Do such gains outweigh the losses?

One study by Berritella et al. (2006) concludes that climate change will ultimately lead, on balance, to significant welfare losses (using income equivalent variations as an index) - especially in western Europe and energy-exporting countries - and in specific countries near the Mediterranean (the currently preferred destination of much European tourism; i.e. Europeans that live in rainy and cool locations tend to go south now, but may find it too hot after warming). However, these losses will not be evenly spread.

\subsection{Expenditure/impact studies}

A host of recreation studies mention or examine the impacts on tourism-dependent communities or countries; people in these areas earn at least some income from tourist expenditures. These studies typically evaluate the activity with regards to the host community, not to the people doing the recreation. While this perspective is important in region-specific economic analysis, most economists we know who specialize in modeling recreation tend to focus their energy on individual-specific demands. This is because it is quite possible that an increase in recreation activity in one region, say Region A, might be offset nationally by a decrease in recreation activity in another, say Region B. In the 'big picture' of national changes, everything 
may cancel out. In other words, many economists take the view that nationally, impacts that balance each other out are of little concern.

However, locally, such impacts may be very important and they are linked to what individuals who go to those regions do in response to climate change. Prices of activities, and perhaps related equipment, may also change in each region as demand and supply changes, but, again, falling ski lift-ticket and ski equipment prices, as an example, in one region might be accompanied by rising prices in another. Furthermore, there may be important linkages between the service industries that directly provide for tourism and recreation, and those service industries that have indirect connections, such as the food and transportation industry.

Such linkages are explored using models that aggregate changes for all individuals into models that are really almost 'macroeconomic' rather than microeconomic. For example, Berrittella et al. (2006) and others use multi-country general equilibrium models to examine global warming impacts on several countries, borrowing the GTAP model from Hertel (1996). The modeling allows the authors to make such statements as 'the main winners are countries whose climate is currently too cold to attract many tourists, such as the former [Soviet Union and Canada] (p. 921)...China and India are hardly affected (p. 922).' While these are large-scale macroeconomic models, it is important to remember that all such models have their roots in what individuals do. They are built by aggregating individual behavior up to the level where 'total' demand and supply changes are estimated.

In summary, climate change may cause widespread losses or gains throughout large regions impacted similarly by climate change, perhaps even inter-country shifts (Berritella et al. 2006 also provide a summary of recent literature along these lines). We do not extensively review the literature in this area of research here, but we are not suggesting that such economic impacts are unimportant. Each region in which climate change will have a substantial impact must, of course, worry about its future and therefore needs to conduct analyses of likely events and consequences. However, estimating the exact magnitudes of the changes they face in the future is going to be difficult, as climate change scenarios vary, and it remains to be seen how people will adapt. For example, Canadian golf destinations might expect an increase in visitors as golf opportunities in southern parts of North America become too hot for comfort and the Canadian regional golf courses become more comfortable with warmer temperatures, but the extent to which this will happen cannot be known with any certainty. Regional economic impact modeling should, therefore, not only analyze demand, supply, and price changes, but also incorporate uncertainty into the projections based on existing, 'macro' style economic models (input-output, computable general equilibrium models, etc.).

\subsection{Existing microeconomic recreation demand studies}

Macroeconomic types of models, as discussed in the previous section, should in fact be consistent with microeconomic model predictions of what individuals do in response to climate change. For example, if micro-oriented researchers or modelers go out and survey 500 Canadian skiers and find that they are representative of what Canadian skiers will do, and if this group of skiers, on average, indicates (via modeling) that its members will take $30 \%$ fewer ski trips in response to global warming of a certain magnitude, then this magnitude (or at least type of response) should be reflected in macro-style models.

We were able to find a few studies on microeconomic demand in the literature. Pendleton \& Mendelsohn (1998) estimate a random utility model (RUMs are discussed in Section 3.4) of sportfishing, with some variation on its development. ${ }^{\mathbf{1}}$ Included in the analysis are temperature and precipitation variables, which are monthly averages, disaggregated by county. There is no time-dimension to the model, but Pendleton \& Mendelsohn (1998) incorporate an ecological model that relates climate variables to fish growth and abundance, which, in turn, influence a catch rate that recreational anglers care about. The focus is on catching trout and pan fish in Maine, New Hampshire, New York (excluding New York City), and Vermont, and Pendleton \& Mendelsohn (1998) find mixed impacts on these recreational anglers' welfare (here welfare is measured by what economists call the Hicksian compensating variation, which is essentially a measure of the angler's WTP to avoid a reduction in catch rates).

Pendelton \& Mendelsohn (1998) conclude that the combined impacts of global change on anglers in this sport fishery may be moderate, and report welfare estimates for a doubling of $\mathrm{CO}_{2}$ in the range of pennies to $10 \mathrm{~s}$ of dollars, depending on the state where the angling sites are. This is an interesting early effort to incorporate climate change, but all of the action is considered via the catch rate variable, and it would have been interesting to see if the probability of visits might also depend on the angler's own sensitivity to temperature and precipitation.

Loomis \& Richardson (2006) do not use the RUM approach, but instead estimate revealed preference regression models with the dependent variable being

1Pendleton \& Mendelsohn (1998) also estimate a version of a re-
creation-demand model known as the hedonic travel cost model 
actual monthly visitation to Rocky Mountain National Park (RMNP) as a function of average daily maximum temperature for a month, and monthly precipitation, as well as snow depth. RMNP is a very scenic Colorado park located about 60 miles from Denver, Colorado. They explored effects in the peak season from May through October, for the years 1987 to 1999. Their 'stated preference' (SP) data collected from on-site visitors can be categorized as contingent behavior data. The authors find that respondents would increase their trips to RMNP, on average, in response to a $4^{\circ} \mathrm{F}\left(2.4^{\circ} \mathrm{C}\right)$ increase, along with a drier climate. They also conclude that the revealed preference (RP) and SP data are consistent with each other. $\underline{2}$

Quite recently, Scott \& Jones (2006) also used regression analysis on daily golf rounds in the Toronto area, modeling these as a function of weather variables for 2 climate change scenarios. They found that the warmer scenario (predicted for 2080) results in a Toronto area golf season that would be quite similar to that currently found in Columbus, Ohio. Again, here we note that several other leisure activity researchers have researched tourism impacts from climate change (see Hamilton \& Tol 2006), but these are not to be confused with studies that carefully consider what individuals who partake in the recreation do in response to climate change, and, more specifically, how their values for the activities change. Assessing what happens to revenue received by a host region is not the same as assessing how a golfer's WTP for a round of golf changes. Recreation-demand models for the individual, discussed more in the following section, consider the latter, but estimated-demand models can indicate changes in visitation due to specific causal factors.

\section{ECONOMIC PRINCIPLES AND CONCEPTUAL FRAMEWORKS}

Data used in these aggregate, macro-style studies typically have no rich details about each individual. We simply know things such as 'tourist visits to country $\mathrm{X}$ in a particular year numbered $1200310^{\prime}$, for example. All rigorous aggregate or macroeconomic models ultimately have some connection to microeconomics, or the theory of what a single individual does, and that microeconomic analysis usually does allow richer details about the individual to be collected.

\footnotetext{
${ }^{2}$ SP and RP data are discussed further, but stated preference means that an individual simply tells the researcher, in some type of survey format, what she prefers, while revealed preferences are measured by watching what a person does. For example, a visitor's number of trips to a lake indicate a possible preference for that lake
}

For example, we can intuit that if a lake has little water in some years and we collect data on the total annual visitation to that lake over time, we will probably see an aggregate effect: fewer total visitors come to the lake in dry years, as compared to wet years. But that intuition is based on the fact that we believe an individual cares about water levels when making a decision to visit a lake. Using microdata, we can ask individuals if they do care about water levels, and, if so, to explain why. Since climate change might lead to dryer conditions in some regions, and lower lake levels, the underlying theory is that, on balance, fewer individual trips might be taken to those lakes when climate change occurs (see the discussion of just this issue by Shaw [1996]).

Economic theory of how people make choices in economics basically assumes that an individual maximizes utility subject to a budget constraint, and this can be applied to recreation and leisure choices. The greatest problem recreation economists have is the non-market goods aspect, discussed above. We know that an individual, when faced with the choice of visiting a Park A versus Park B, C, D, etc. considers the implicit 'trip price' of such visits based on their travel cost and travel time (even though there is no market price), as well as key characteristics (natural amenities and/or constructed facilities) of each park. Using characteristics of leisure and outdoor recreation activity destinations to explain a person's choices has been done since the 1970s, at least. So, it is possible to suggest a theoretical modeling framework that includes climate change (or temperature or something related) as a characteristic or as one of the qualities of leisure/recreation locations affected by climate change.

Wall (1998) and several others have considered climate change impacts on recreation and how they will affect tourism and recreation, and J. B. Loomis (unpubl.) summarizes these types of direct and indirect impacts in a convenient flow chart (see Fig. 1 and USEPA 2008). Table 2 also lists some of the features of general leisure (top half) and recreational activityspecific destinations that are going to be impacted by climate change. It is important to consider both the demand that people have for activities and the supply of resources (including places to do them) to facilitate doing those activities. On the demand side, temperature and precipitation may influence many activities, as some simply cannot be performed in certain kinds of weather, at least by most normal individuals. ${ }^{3}$

\footnotetext{
${ }^{3}$ Here, we are aware of the fact that some individuals voluntarily do marathons and such things in places like Death Valley, with temperatures exceeding $100^{\circ} \mathrm{F}$
} 


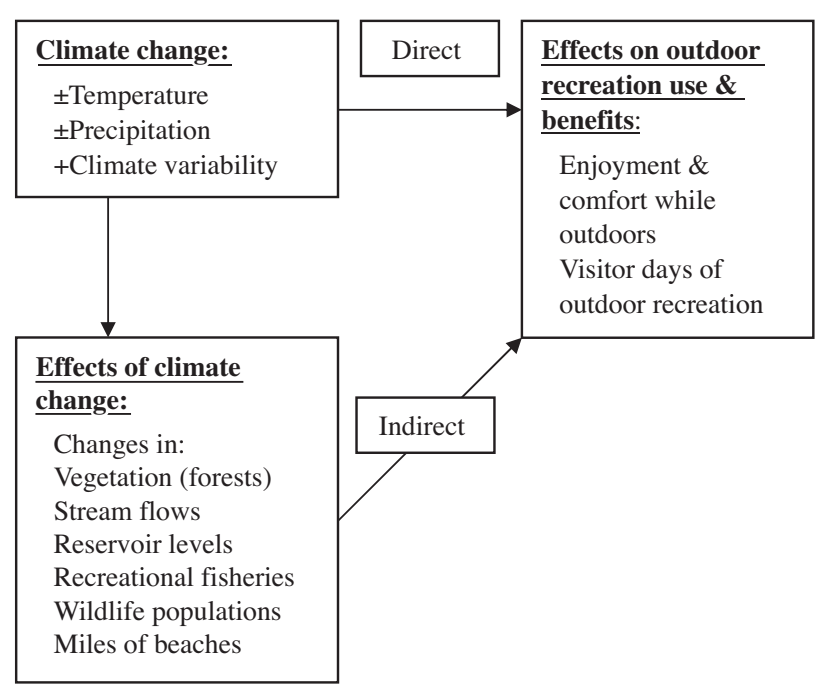

Fig. 1. Direct and indirect effects of climate change on recreation

On the supply side, at some extreme projections of climate change impacts, habitat for certain species will be lost, and activities dependent on those species (e.g. watching animals, hunting them; enjoying types of trees in forests, hiking among them) will likely be eliminated within a given region. At one end of the spectrum, global warming may simply lead to the disappearance of golf courses and ski areas in some areas that become too hot for the enjoyment of them. At the other extreme, it is possible that warming in cold areas may increase participation in some activities. So, what economic modeling framework can incorporate all, or at least some of these variables?

Table 2. Features of leisure and recreation types affected by climate change. General leisure: urban outdoor activities, e.g. tennis, golf, jogging, biking, park visits

\begin{tabular}{|c|c|}
\hline Activity & Feature \\
\hline General leisure & $\begin{array}{l}\text { Daily temperature } \\
\text { Precipitation/humidity } \\
\text { Sunshine } \\
\text { Extreme events (hurricanes, tornadoes) }\end{array}$ \\
\hline \multicolumn{2}{|c|}{ Site-specific outdoor recreation } \\
\hline Hiking, biking & $\begin{array}{l}\text { Forest composition, vegetation cover, } \\
\text { density }\end{array}$ \\
\hline Fishing, boating & $\begin{array}{l}\text { Water quality, quantity, fish habitat } \\
\text { and catchability }\end{array}$ \\
\hline Hunting & Animal habitat, availability \\
\hline Bird/animal watching & Animal, species availability \\
\hline Beach-going & Sea level, loss of beach/coastal areas \\
\hline Skiing/winter sports & Snow loss \\
\hline Rock climbing & Storm intensity, frequency \\
\hline
\end{tabular}

\subsection{Conceptual microeconomic frameworks}

We consider 2 approaches (the first only briefly) that might be taken to address fundamental questions. Each might be better suited to address specific questions that society has and, in theory, be more effective in answering specific research and policy questions. For example, if the effect of climate change is believed to be reflected in prices and quantities of land used for tourism then the Ricardian approach might be more fruitful. If social scientists are interested in how individuals will respond to climate change, the utility theoretic model of individual behavior may be a more suitable analysis approach. Space limits any discussion of further economic frameworks.

\subsection{Ricardian analysis}

The first microeconomic approach that might be taken to model tourism and recreation impacts, which to our knowledge has not been pursued, would follow the 'Ricardian' analysis developed by Mendelsohn et al. (1994). The essence of the Ricardian approach is that the effects of climate change on farmland values are considered, as opposed to the impacts on crop output (the usual approach taken by economists). Analogous to the farmland value study by Mendelsohn et al. (1994), one might consider that land is used to provide recreational services. For example, golf courses are large tracts of land that have likely been converted from some other use. Conversion of lands for recreational purposes must factor in the role of demand and, when fees can be charged, the likely equilibrium price that can be observed in leisure markets. Consider again, for example, ski areas that occupy mountain areas and are able to charge skiers for lift tickets. If climate change negatively impacts the ski experience at an area, then demand may fall, and, eventually, the ski area operator must consider reducing prices. Ultimately, if priced out of the market, the value of the ski area land will change to its value in the next best use.

In principle, Ricardian analysis could be used to examine land value changes for recreation services such as skiing and golfing. If one is most interested in such overall market value changes and how these may affect land markets and other markets that relate to land prices, then this approach would be quite fruitful to pursue. Strengths and weaknesses of the approach are discussed in the following section. 


\subsection{Individual microeconomic demand modeling}

A second possible economic approach we describe follows on building up individual demands from the random utility model in order to better understand how individuals really might respond to climate change impacts. The utility of an individual $(U)$ depends on consumption of private goods/services and some public goods, including climate. In terms of climate, the utility of an individual might incorporate temperature, wind, and precipitation, collectively denoted by $Z$. This collective influence attempts to avoid concerns some have raised that only temperature matters in assessing climate change impacts, when in fact precipitation or cloud cover may be equally important (Gössling \& Hall 2006). We note also that perceptions of these climate and weather variables, rather than objective measures, may be important because many tourists or recreational users pay little attention to actual data and forecasts in planning their trip (Maddison 2001).

In usual microeconomic models the utility a person receives comes from consumption of a bundle of private goods, $X$, some of which may depend on $Z$, and $U$ can also be influenced by personal traits, situations or characteristics, $S$, which can, in turn, depend on $Z$. For example, an individual's consumption of tennis equipment may depend on $Z$, and a person's health status might also be related to climate (weather conditions can affect pollution levels, which, in turn, affect respiratory conditions). In this general world (suppressing a separate subscript to denote individual $i), U=U[X(Z)$, $Z, S(Z), L]$, where $L$ is leisure time. ${ }^{4}$ Maximizing $U$ subject to a budget constraint leads to optimal demand equations for goods $X$ and leisure time $L$. However, an immediate problem with this standard framework for those interested in climate change arises when one considers $\partial U / \partial Z$.

The social scientists interested in individual responses want to know: What is the effect of $Z$ on $U$, holding everything else constant? This tells us whether an increase in $Z$ causes $U$ to go up or down, i.e. the person is made better, or worse off. Because $X$ and $S$ may both depend on $Z$, and because $Z$ can also contribute to utility with no connection to $X$ or $S$ in this most general form, the answer is unknowable. The effect of $Z$ on $U$ will depend on the person, the recreational activities she participates in, the region in which she lives, and the direction of and components of changes in $Z$ as climate change occurs. There are just too many variables for the economist to arrive at any conclusions.

\footnotetext{
$\underline{4}$ The economist's traditional labor-leisure choice derivation may include labor time in the utility function, and optimization in the model leads to the individual's labor supply function, or their 'leisure-demand' function
}

\subsection{Weak separability}

To make this more tractable, the economist must make an additional simplifying assumption, called separability, which follows from a theory that allows for multi-stage budgeting. In Fig. 1, for example, an illustrative series of decisions is presented, where the individual makes allocation decisions for goods consumed, leisure, and leisure activities.

Assume that the utility $(U)$ from engaging in a particular activity is 'separable' from the utility for other activities, so the utility function takes a particular functional form mathematically. For example, we assume we can formally isolate utility from fishing at lakes, from the utility function for watching television, or from the utility related to playing golf. Formally, if $U$ is the general or grand utility function for all things that lead to preferences, we are saying that with 'weak' separability $U$ can be written as $U=U\left[\mathrm{U}_{1}(), \mathrm{U}_{2}(), \ldots\right.$, $\mathrm{U}_{n}()$ ], with up to $n$ 'sub-utility' functions.

This assumption of weak separability allows analysis of terms such as $\partial U_{1} / \partial Z$, with the assumption that the partial effect does not consider all impacts on all of the sub-utility functions. Let the activity of interest in an analysis be $L_{\mathrm{f}}$, say fishing trips. Reconsider our earlier utility function in this way: the original utility function $U=U[X(Z), Z, S(Z), L]$ will become $U=U\left\{U_{1}[X], U_{2}\left[L_{\mathrm{f}}\right.\right.$,

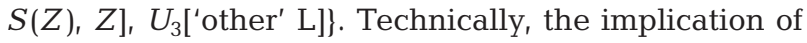
this utility structure is that when we model how a person changes her fishing trips in response to something such as climate change, we need not worry about the effect of the price of golfing on fishing, or the effect of another characteristic of golfing and how it relates to fishing behavior - these can be excluded from $U_{2}$ and considered with 'other $L$.' This is a restrictive assumption, very often made in empirical studies of economic behavior.

To continue with an example used in several places in this paper, suppose we consider a microeconomic model of fishing demand that would incorporate climate change, as Pendleton \& Mendelsohn (1998) do. Utility for fishing, $U_{\mathrm{f}}$, is assumed to be dependent on fishing quality and the price of fishing trips. Many recent analyses make the model into one of choice among various fishing sites $(j)$, and consider the conditional indirect utility function, $V_{j}$, i.e. the utility the individual obtains after choosing to visit Fishing Site $j$. (Indirect utility is explained in Appendix 1)

Let $V_{j}$ be given by:

$$
V_{j t}=V_{j t}\left(\mathrm{cr}_{j}, Y-\mathrm{TC}_{j}, t e m p_{j t}, r_{j t}, \mathrm{sb}_{j}\right)
$$

Indirect utility in Eq. (1) is a function of income $(Y)$ less travel costs (TC) (the non-market valuation economist's proxy for the trip price) to Site $j$, but includes other selected variables that might relate climate change to utility. It seems reasonable to omit sea levels 
and ocean currents for freshwater fishing, for example, unless a person substitutes between marine and freshwater recreational fishing. For some anglers that might be an option.

In Eq. (1) we introduce a time dimension ${ }_{t}$ ) for temperature (temp) and precipitation $(r)$ at Site $j$, including both variables instead of the composite 'weather variable' $(Z)$, i.e. we include temp and $r$, respectively. We also include cr as the catch rate for fish, and sb is scenic beauty. Note that temperature is site specific, suggesting that if it provides utility in certain ranges, that one experiences it by being there. While in one sense, including temperature in the utility function might be done so that temperature is somewhat divorced from or dependent on actual use, it may be most logical for temp to be tied to being at a recreation destination and the implied values from this are going to be use values. $\frac{5}{}$ In economics, just how temperature is assumed to enter the indirect utility function dictates whether we are assuming people only care about temperature if they actually engage in recreation (taking trips to destinations), or whether they might care about temperature changes even when they do not actively engage in outdoor recreation.

In this fishing model, catch rates can be made specific to an angler's target species. They might themselves be a function of climate (water temperature), and this formulation [ $\mathrm{cr}(\mathrm{temp})]$ could be introduced as well (see Pendleton et al. 1998). Scenic beauty might be a function of vegetation cover and type, in turn potentially affected by climate change. The reason why this might be important is that it may well be that utility varies depending on temperature at a given time, and, thus, individuals might consider different destinations at different times of the year, if they face flexible work schedules that allow intertemporal substitution. However, some of the studies that have used natural variations in temperature (monthly, seasonal, and inter-annual) have found that, while visitation increases with initial increases in temperature, as temperature increases further, visitation actually decreases (Hamilton \& Tol 2006, Loomis \& Richardson 2006).

The RUM adds an error term for investigator error to Eq. (1), and then the theory assumes that when $V_{j}>V_{k}$ (Site $k$ not equal to Site $j$ ), the individual will choose to visit Site $j$ rather than $k$. When the distribution of the error term is specified, the resulting model is then a revealed preference RUM, and the usual approach is to make assumptions that lead to the multinomial logit model, or one of its variants.

\footnotetext{
${ }^{5}$ The structure of the utility function determines whether one is assuming weak complementarity or not. With weak complementarity, temperature matters to utility only if the person takes a trip there. Otherwise, temperature at some site matters to a person, even if they never go, allowing non-use values
}

In such a way, in theory, we might begin to investigate the individual's demands for freshwater recreational fishing sites that depend on amenities tied to climate change. The above framework would allow a person to substitute between freshwater destinations with differing levels of climate variables, holding travel costs constant. Naturally, if substitution involves an enormous cost, perhaps because of travel to cooler climates that are 500 miles north, the individual is going to be less likely to do this. The needed data would include preferences and choices over a time period where we can observe temperature and other seasonal changes. In addition, if links between time periods are allowed (i.e. behavior indicated by 'I didn't go to Whistler Mountain in February because I went in January already...'), then the models can become quite complex (Swait et al. 2003).

By breaking down an individual's leisure activities into subgroups as above, it is theoretically possible to explore disaggregated recreational activities and the impacts of climate change on each. Essentially, random utility modeling such as the above is telling us about individual demands and how they depend on climate change variables. However, the difficulty comes in determining the relationship between the narrowly focused demands. If we expect, for example, that over time people will begin to substitute between activities, and not just substitute between recreation destinations, then the models must be developed to accommodate that. Larger structures, such as nested logit models, can handle that. For example, in nested logit specifications, we might begin with exploration of whether an individual chooses, during some summer season, to play golf, or go backpacking in the mountains, or go to the beach. Taking part in or ceasing activities - or quitting them altogether — can be part of such models (Shaw \& Ozog 1999). The limitation is not in the models we have at our disposal, but in collecting the needed data on individuals.

A final note here involves the limitations of what is an RP approach above, which relies solely on observing what people do (e.g. take trips to Site $j$ or not). We have laid out the theory as if we can simply observe what people do in response to climate change. However, many changes have not yet occurred, so there is no way to map the relationship between future expected changes and observed behavior. To deal with this problem, many modelers supplement RP data with SP data, which simply put, asks people to state what they would do in response to something like climate change. ${ }^{\mathbf{6}}$

\footnotetext{
${ }^{6}$ SP data come in many forms, including direct valuation questions (How much would you be willing to pay, or, in discrete form, would you be willing to pay \$X per year to avoid a temperature increase of $2^{\circ} \mathrm{C}$ ?), or stated choice models. Stated choice models include conjoint analyses (Swait et al. 2003)
} 
An example of a study that combines RP and SP recreation data and focuses on climate change impacts is that by Loomis \& Richardson (2006). Their surveybased models ask how visitors will change their behavior (if they say they will) if a change in temperature or precipitation occurs. Combined SP-RP models are now fairly common in the recreation demand literature, and they are often critical extensions of basic RP frameworks because many events simply have not occurred yet, making RP-based data quite limited for inferences about some behaviors. Climate change impacts are an excellent example.

Once one opens the door with the use of SP data, it is possible that non-use values can result, depending on the types of questions that are asked. For example, consider the importance of a species to an individual. That species might be important for any number of reasons including for harvest (food/game to hunt), to see in the wild (non-consumptive recreational use), or simply because a person gets satisfaction knowing the species exists and is protected from extinction. This latter non-use might be because a parent wants the species available for viewing for their children, for friends, or because an individual is simply somehow better off with the species existing than not. For unique species or unique natural environments, these non-use values can be larger than recreation-use values due to the non-rival and non-excludable nature of non-use values (Walsh et al. 1984).

\subsection{Comparing the Ricardian and individual- demand approaches}

The strength of the Ricardian approach is that it is more consistent with general equilibrium style models than the individual-demand approach. However, first we note that in some instances lands are public lands and there is no readily observable market price of the land (e.g. many US ski areas lease public land from the US Forest Service), so this analysis might entail data collection and analysis along the lines of non-market valuation. Second, one must be sure that all causal factors that lead to land value changes have been accounted for, so that the influence of climate change impacts can be isolated. We have some concerns that data that would need to be collected for the Ricardian approach applied to the tourism/recreation sector would be greater than that required for the individualdemand approach.

Many believe that while scientists might consider what the individual does in response to climate change for one activity, as in the individual-demand approach laid out above, we have to further consider all of the activities that an individual engages in over time. This idea points out the limitations of the individualdemand model. It may offend some or stretch the imagination to think so, but individuals may make substitution decisions that at first seem ludicrous. For example, passionate skiers may strongly believe they will never take up golfing in lieu of skiing, but how do they really know what they will do until faced with a fundamentally different choice situation?

Second here, related prices and quantities in markets for recreational activities, as well as mitigation and adaptation decisions of suppliers, may fundamentally play a role in what happens in the future in response to climate change, and these are, of course, related to one another. With changes in expected demand, suppliers can make choices in response, including changing prices of services offered or fundamentally changing the way that they provide services. The ski industry may or may not choose to make snow if they can feasibly do so, in areas where snowfall decreases. If they do so, they will try to pass on higher costs related to snow-making to skiers in the form of higher lift-ticket prices. Skiers may or may not choose to pay them, depending on their demand.

Similarly, the golf industry in Canada might choose to offer package deals to lure tourists up from midwestern and southern states in the United States, where it has become too hot to play golf in certain seasons. So, while the individual-demand approach is valuable in informing social scientists about partial equilibrium effects for one activity, a well-constructed economic analysis of climate change impacts needs to consider both demand and supply effects in prediction. This is work that is just starting to be done, and, as was seen above, if the simplistic individual-demand model is made more complicated, many challenges lie ahead. Next, we briefly discuss of what we think are research gaps that need plugging.

\subsection{Research gaps}

First, as noted in the Pendleton \& Mendelsohn (1998) study, most recreation-demand analyses assume that the supply of natural resources is fixed or unchanging and focus on how demand varies with climate change. Other studies look only at the supply side. For example, they examine how climate change affects the amount of snow for skiing, fish growth, or availability of beaches. No studies we know of examine both sides simultaneously to explore the net effects. To do so would require that demands respond to changes over time, and adjustments or adaptation be considered. As an example, Loomis \& Crespi (1999) find that there is a $14 \%$ increase in the demand for beach recreation as temperatures change and some scientific analyses of 
climate change predict an increase in sea level rise that would result in loss of beaches, but an integrated study would factor in the losses in the beaches in considering the demand for beach recreation under climate change scenarios, perhaps through increased congestion at beaches.

Second, as suggested above, climate change analysis is plagued with uncertainty (Heal \& Kriström 2002) and any economic analysis really should incorporate that. Very few recreation-demand studies have incorporated the role of perceptions of variables, or have incorporated risk or uncertainty (see the review and suggestions for a framework in Shaw et al. 2006). These 2 issues are linked in that many people perceive of risks differently than scientists, so one might well encounter a discrepancy in individuals' views of say, the risks of warmer temperatures at any given time or place versus the views of climate change scientists. In models that allow for risks to play a role, 'expected' utility maximization leads to 'expected' demands: in both, the probabilities of outcomes enter the decision-making framework. This sounds simple and plausible, but when probabilities of outcomes or states are not easily known, the models become much more complex. An additional complication occurs when risks are endogenous, and climate change is exactly such a situation (Heal \& Kriström 2002). This is because society has 2 real choices that may influence risks associated with climate change. The first is to mitigate or to avoid climate change impacts by taking actions now to slow the effects. The second is to adapt to climate change. While the latter does not change the probability of warming, it may, for example, change the probability of dying from a consequence such as heat-stroke.

Third, within the context of the models such as the one illustrated above, several gaps remain in the details. We still know of no study that has carefully derived a model that allows for wide geographical substitution and, perhaps, inter-temporal substitution. Economists generally assume that people are flexible and can adapt to changes. However, while recreation economists have 100s of studies showing how people substitute between recreation destinations within close proximity of one another, there are very few studies of substitution between activities, 2 countries in different climate zones or over different seasons. Intuition suggests that people may be able to swap a fishing trip in June for a fishing trip in September. There is some recent evidence of this (Kim et al. 2007), but these issues need to be explored in more depth so that the degree of adaptation to climate change can be measured.

However, probably the largest remaining economic research gap is in the examination of ecosystem impacts owing to climate change, and the associated non-use values - such as existence values - affected by climate-induced changes to natural environments and the species contained within. We typically think of recreation involving use of resources; thus, the above has focused on models that generate use values. However, it is possible that some people may be willing to pay something to prevent climate change from affecting others' recreational opportunities, not their own, a form of altruism. In addition, rapid climate change may outstrip species' ability to adapt and threaten them with extinction. This may already be happening with the Arctic Polar Bear. We know that many people would pay to prevent extinction of species from happening (Loomis \& White 1996). Many of the same SP tools can be applied to estimate the losses in non-use value associated with climate change.

\section{FINAL THOUGHTS}

In this article we have tried to lay out a framework for analyzing the economic effects of climate change on outdoor recreation. However, most of what we have said here also pertains to almost all economic analyses of other impacts of climate change, including those on the agricultural sector and on ecosystems. Some readers may be pessimistic or overwhelmed by the current lack of data we report about, as compared to what data we believe are needed to do careful economic analyses. Our thought on this is that as society faces more alarming news about climate change, more resources will be invested into data collection to get the answers we need. Society often chooses such investments only when the problems ahead are generally agreed upon and are perhaps even glaring. Until science can provide answers to reduce future climate uncertainty, many would likely wish to adhere to the precautionary principle adopted by many European nations, which mandates that at the very least, we err on the side of being over-cautious when making decisions that would increase our contribution to global warming (Heal \& Kriström 2002).

Acknowledgements. The authors thank 3 anonymous reviewers and the editor for helpful comments which have led to improvements in the manuscript. We also thank Michele Zinn for helping edit the final version of the manuscript.

\section{LITERATURE CITED}

Agrawala S (ed) (2007) Climate change in the European Alps: adapting winter tourism and natural hazards management. OECD, Paris

Berritella M, Bigano A, Roson R, Tol RSJ (2006) A general equilibrium analysis of climate change impacts on tourism. Tourism Manag 27:913-924 
Bigano A, Hamilton JM, Maddison DJ, Tol RSJ (2006) Predicting tourism flows under climate change: an editorial comment on Gössling and Hall. Clim Change 79:175-180

Bürki R, Elsasser H, Abegg B (2003) Climate change and winter sports: environmental and economic threats. Presented at the 5th World Congress on Sport and Environment, Turin, Italy (December)

Gössling S, Hall CM (2006) Uncertainties in predicting tourist flows under scenarios of climate change. Clim Change 79: 163-173

Hamilton J, Tol R (2006) The impact of climate change on tourism and recreation. In: Schlesinger $M$ (ed) Humaninduced climate change-an interdisciplinary assessment. Cambridge University Press, Cambridge, p 147-155

Heal G, Kriström B (2002) Uncertainty and climate change. Environ Resour Econ 22:3-39

Hertel TW (1996) Global trade analysis: modeling and applications. Cambridge University Press, Cambridge

IPCC (Intergovernmental Panel on Climate Change) (2007) Summary for policy makers. In: Solomon S, Qin D, Manning M, Chen Z and others (eds) Climate change 2007: the physical science basis. Contribution of Working Group I to the 4th Assessment Report of the IPCC. Cambridge University Press, Cambridge. Available at: www.ipcc.ch/ pdf/assessment-report/ar4/wg1/ar4-wg1-spm.pdf

Kim H, Shaw WD, Woodward RT (2007) Distributional consequences of fees in a discrete choice model of recreation demand with incomplete data: an application to marine fishing. Land Econ 83:561-574

Loomis JB, Crespi J (1999) Estimated effects of climate change on selected outdoor recreation activities in the United States. In: Mendelsohn R, Neumann J (eds) The impact of climate change on the United States economy. Cambridge University Press, Cambridge, p 289-314

Loomis JB, Richardson R (2006) An external validity test of intended behavior: comparing revealed preference and intended visitation in response to climate change. J Environ Plann Manag 49:621-630

Loomis JB, White DS (1996) Economic benefits of rare and endangered species: summary and meta analysis. Ecol Econ 18:197-206

Maddison DJ (2001) In search of warmer climates? The impact of climate change on flows of British tourists. Clim Change 49:193-208

Mendelsohn R, Markowski M (1999) The impact of climate change on outdoor recreation. In: Mendelsohn R, Neumann J (eds) The impact of climate change on the United
States economy. Cambridge University Press, Cambridge, p 267-288

Mendelsohn R, Nordhaus W (1999) The impact of global warming on agriculture: a Ricardian analysis-reply. Am Econ Rev 89:1053-1055

Mendelsohn R, Nordhaus W, Shaw D (1994) The impact of global warming on agriculture: a Ricardian analysis. Am Econ Rev 84:753-771

Pendleton LH, Mendelsohn R (1998) Estimating the economic impact of climate change on the freshwater sportsfisheries of the northeastern US. Land Econ 74:483-496

Scott D, Jones B (2006) The impact of climate change on golf participation in the Greater Toronto Area: a case study. J Leisure Res 38:363-380

Scott D, McBoyle G, Minogue A, Mills B (2006) Climate change and the sustainability of ski-based tourism in eastern North America: a reassessment. J Sustainable Tourism 14: 376-398

Shaw WD (1996) Problems with estimating the economic impacts from averting climate change: a look at water resources. Water Resour Res 32:2251-2258

Shaw WD, Ozog M (1999) Modeling overnight recreation trip choice: application of a repeated nested multinomial logit model. Environ Resour Econ 38:397-414

Shaw WD, Riddel M, Jakus P (2006) Valuing environmental changes in the presence of risk: an update and discussion of some empirical issues. In: Folmer $\mathrm{H}$, Tietenberg $\mathrm{T}$ (eds) International yearbook of environmental and resource economics: a survey of current issues: 2005/2006. Edward Eglar Press, Northampton, MA

Swait J, Adamowicz W, van Bueren M (2004) Choice and temporal welfare impacts: incorporating history into discrete choice models. J Environ Econ Manag 47:94-116

USEPA (US Environmental Protection Agency) (2008) Analysis of the effects of global change on human health and welfare and human systems. Draft report (May). Available at: www.climatescience.gov/Library/ sap/sap4-6/sap4-6-draft3.pdf

Wall G (1998) Implications of global climate change for tourism and recreation in wetland areas. Clim Change 40: 371-389

Walsh R, Loomis J, Gillman R (1984) Valuing option, existence and bequest demands for wilderness. Land Econ 60:14-29

WTO (World Tourism Organization) (2003) Climate change and tourism. In: Proceedings of the 1st International Conference on Climate Change and Tourism. WTO, Madrid

Appendix 1. On indirect utility

To obtain the 'indirect' utility function, first assume the individual maximizes utility, $U$ subject to budget constraints. The solution to this utility-maximization problem results in demand equations for goods and activities, $X^{*}$ and Act ${ }^{*}$, where the asterisks reflect 'optimal' economic choices. Act* might be, for example, the optimal number of fishing trips a person takes to maximize her utility from fishing. To obtain the 'indirect' utility function $(V)$ we replace $U(x$, Act) with utility at these optimal levels, $U\left(x^{*}\right.$, Act $\left.^{*}\right)$, to obtain $V(p, Y)$, where $p$ is the price of $x$ and $Y$ is income. The indirect utility function, therefore, has relevant prices and income, as well as characteristics of the goods as arguments rather than levels of goods. 